\title{
Callous and unemotional traits in children and adolescents living in Great Britain
}

Paul Moran, Tamsin Ford, Georgia Butler and Robert Goodman

\section{Summary}

Few studies have assessed psychopathic traits in community samples of young people. We investigated the predictive utility of callous and unemotional traits in a representative sample of 5770 young people from Great Britain. Teachers provided information on the presence of callous and unemotional traits and parents completed the Strengths and Difficulties Questionnaire to determine the level and impact of psychiatric problems at baseline, 12 and 24 months later.
Baseline callous and unemotional trait scores independently predicted the number and intensity of conduct, emotional and hyperactivity symptoms at follow-up. Callous and unemotional traits are longitudinally associated with the level and impact of childhood psychiatric problems.

\section{Declaration of interest}

None.
Over the past decade, interest in childhood psychopathy has grown. ${ }^{1,2}$ Although the concept is controversial, if 'fledgling psychopaths ${ }^{3}$ could be successfully identified, this might represent a breakthrough in the prevention of persistent antisocial behaviour. Frick and colleagues have highlighted the importance of identifying callous and unemotional traits as a potential marker for life course persistent antisocial behaviour. ${ }^{1,4}$ However, few studies have assessed callous and unemotional traits in community samples and data on their predictive utility are sparse. We set out to examine the correlates and predictive utility of callous and unemotional traits in a large epidemiologically representative sample of young people from Great Britain.

\section{Method}

A stratified random sample of 10496 families was invited to participate in the British Child and Adolescent Mental Health Survey 2004; a total of 7977 (76\%) responded. All study procedures received multicentre research ethics committee approval and informed consent was obtained from parents. Children in the survey were aged 5-16 years. All parents had a face-to-face interview during which they provided socio-demographic details and completed the 12-item General Health Questionnaire ${ }^{5}$ and the Strengths and Difficulties Questionnaire (SDQ), a wellvalidated measure of childhood psychopathology. ${ }^{6}$ Nominated teachers were mailed a questionnaire (if the family consented). Informed by previous factor analyses ${ }^{1,4}$ the teacher questionnaire included seven statements relating to the presence of callous and unemotional traits in the index child:

1 Makes a good impression at first but people tend to see through him/her after they get to know him/her.

2 Shallow or fast-changing emotions.

3 Too full of his/her own abilities.

4 Is usually genuinely sorry if s/he has hurt someone or acted badly.

5 Can seem cold-blooded or callous.

6 Keeps promises.

7 Genuine in his/her expression of emotions.

The items were all rated on a three-point $(0,1,2)$ Likert scale (not true, partly true, certainly true). Possible total scores on the scale ranged from 0 to 14 , with items $1,2,3$ and 5 being scored 2 for 'certainly true' and the remaining items scored 2 for 'not true'. A principal component analysis showed that the seven items from the scale loaded on to one component, with an eigenvalue of 2.44 (35\% of the variance). The scale demonstrated good internal consistency (Cronbach's $\alpha=0.78$ ).

At 12 and 24 months, parents who had participated in the baseline survey and had agreed to be followed up were posted an SDQ. Associations between teacher-rated callous and unemotional trait score and 12- and 24-month parent-rated outcomes were examined using longitudinal linear regression. Outcomes and continuous predictor variables were transformed into $z$-scores (zero mean and unit standard deviation) so that the magnitudes of regression coefficients could be compared on a common scale. We included appropriate interaction terms in the models in order to test whether the effects of callous and unemotional traits were modified by age or gender. All analyses were performed using Stata version 8.1 for Windows.

\section{Results}

Callous and unemotional trait score ratings were obtained from 5770 teachers (55\% of the original sample) and the mean score was 1.65 (s.d.=2.25). Callous and unemotional trait score was significantly associated with male gender, older age, Black and minority ethnicity, fair or bad general health, parental common mental disorder, larger family size and lower household income. Outcome data (12- and 24-month) were obtained for 4609 young people; an $80 \%$ response rate. The following groups were overrepresented among those with missing trait ratings or missing outcome data: older children, those from larger families, those with poorer general health, and those from Black and minority ethnic groups.

Table 1 displays the results of longitudinal linear regression models examining adjusted associations between baseline predictor variables and conduct, hyperactivity and emotional symptoms at 12 and 24 months combined. Callous and unemotional traits, lower household income, the presence of parental common mental disorder and the number of SDQ symptoms at baseline were all independently associated with the three symptom domains at follow-up. For conduct symptoms, there was weak evidence for an interaction between callous and unemotional traits and gender $(P=0.07)$, with callous and unemotional traits being more strongly associated with conduct symptoms in boys (coefficient $=0.09 ; \quad P<0.001$ ) than in girls (coefficient $=0.05$; $P<0.05)$. The total SDQ symptom and impact scores at 12 and 
Table 1 Results of longitudinal linear regression models showing the effect of baseline predictor variables on conduct, hyperactivity and emotional symptoms at 12 and 24 months ( $n=4609$ for all models)

Regression coefficient

\begin{tabular}{|c|c|c|c|}
\hline \multirow[b]{2}{*}{ Predictor variable } & \\
\hline & Conduct symptoms & Hyperactivity symptoms & Emotional symptoms \\
\hline Callous and unemotional traits ${ }^{a}$ & $0.07 * * *$ & $0.07 * * *$ & $0.04^{* * *}$ \\
\hline $\mathrm{Age}^{\mathrm{a}}$ & 0.01 & $-0.03^{\star *}$ & -0.02 \\
\hline Gender (girls $v$. boys) & 0.01 & $-0.08 * * *$ & $0.14^{* * *}$ \\
\hline Total baseline SDQ scores $^{a}$ & $0.57 * * *$ & $0.63^{* * *}$ & $0.51 * * *$ \\
\hline Ethnicity (other $v$. White) & -0.001 & 0.02 & $0.08^{*}$ \\
\hline Household income $^{a}$ & $-0.04 * * *$ & $-0.05^{* * *}$ & $-0.06 * * *$ \\
\hline Parental common mental disorder (present $v$. absent) & $0.14^{* * *}$ & $0.09 * * *$ & $0.21 * * *$ \\
\hline Child's general health (fair or bad $v$. good) & 0.04 & 0.07 & $0.11^{*}$ \\
\hline Family size ${ }^{a}$ & $0.02 *$ & -0.002 & 0.02 \\
\hline Overall $R^{2}$ & 0.35 & 0.47 & 0.29 \\
\hline $\begin{array}{l}\text { SDQ, Strengths and Difficulties Questionnaire. } \\
\text { a. Entered as a transformed continuous variable. } \\
\star{ }^{*} P<0.05 ; * \star P<0.01 ; * \star \star P<0.001 \text {. }\end{array}$ & & & \\
\hline
\end{tabular}

24 months were also independently associated with the baseline callous and unemotional trait symptom score (adjusted coefficient for SDQ score $=0.06 ; P<0.001$; adjusted coefficient for impact score $=0.05 ; P<0.001)$. There was evidence of an interaction between callous and unemotional traits and gender $(P=0.03)$, with callous and unemotional traits being more strongly associated with the SDQ impact score in boys (coefficient $=0.07 ; P<0.001$ ) than in girls (coefficient $=0.03 ; P=0.08$ ).

\section{Discussion}

In this study we have provided preliminary evidence to show that the presence of callous and unemotional traits is longitudinally associated with the level and impact of childhood psychopathology and that this is independent of the effects of established risk factors for childhood psychiatric illness. The strongest predictor of psychiatric symptoms at follow-up was the total baseline symptom score, and in comparison, the predictive value of callous and unemotional traits and socio-demographic factors was small. Nevertheless, few studies have assessed the predictive utility of callous and unemotional traits in community samples of young people 7,8 and to the best of our knowledge, the present study is the largest to date. The presence of callous and unemotional traits in young people, particularly in boys, seems to confer a vulnerability to additional mental health problems and this finding has both clinical and research implications. From a clinical perspective, screening for the presence of callous and unemotional traits may assist health professionals to identify a particularly vulnerable group of young people. From a research perspective, adding questions on personality traits to childhood psychiatric questionnaires may increase their predictive value.

Strengths of the study include the use of a large representative sample of young people and the fact that we obtained information from two sources, parents and teachers, permitting us to minimise rater bias. However, despite the fact that the callous and unemotional trait scale demonstrated factorial unity and good internal consistency, further research is required to establish its detailed psychometric properties. In addition, higher callous and unemotional trait scores were associated with groups of children overrepresented in the missing data group. Our analyses were therefore conducted on a 'healthier than normal' population and the findings require replication.

Paul Moran, MSC, MD, MRCPsych, Health Services and Population Research Department, Institute of Psychiatry, King's College London; Tamsin Ford, MSc, PhD, MRCPsych, Department of Child and Adolescent Psychiatry, Institute of Psychiatry, King's College London; Georgia Butler, MSC, Health Services and Population Research Department, Institute of Psychiatry, King's College London; Robert Goodman, PhD, FRCPsych, Department of Child and Adolescent Psychiatry, Institute of Psychiatry, King's College London, London, UK

Correspondence: Paul Moran, Health Services Research Department Institute of Psychiatry, De Crespigny Park, London, SE5 8AF, UK. Email: paul.moran@iop.kcl.ac.uk

First received 20 December 2006, final revision 2 October 2007, accepted 9 October 2007

\section{References}

1 Frick PJ, O'Brien BS, Wootton JM, McBurnett K. Psychopathy and conduct problems in children. J Abnorm Psychol 1994; 103: 700-7.

2 Dadds MR, Perry Y, Hawes DJ, Merz S, Riddell AC, Haines DJ, Solak E, Abeygunawardane Al. Attention to the eyes and fear-recognition deficits in child psychopathy. Br J Psychiatry 2006; 189: 280-1.

3 Lynam DR. Early identification of chronic offenders: who is the fledgling psychopath? Psychol Bull 1996; 120: 209-34.

4 Frick PJ, Bodin SD, Barry CT. Psychopathic traits and conduct problems in community and clinic-referred samples of children: further development of the psychopathy screening device. Psychol Assess 2000; 12: 382-93.

5 Goldberg D, Williams P. A User's Guide to the General Health Questionnaire. nfer-Nelson, 1988.

6 Goodman R, Ford T, Simmons $\mathrm{H}$, Gatward R, Meltzer $\mathrm{H}$. Using the Strengths and Difficulties Questionnaire (SDQ) to screen for child psychiatric disorders in a community sample. Br J Psychiatry 2000; 177: 534-9.

7 Frick PJ, Stickle TR, Dandreaux DM, Farrell JM, Kimonis ER. Callousunemotional traits in predicting the severity and stability of conduct problems and delinquency. J Abnorm Child Psychol 2005; 33: 471-87.

8 Dadds MR, Fraser J, Frost A, Hawes DJ. Disentangling the underlying dimensions of psychopathy and conduct problems in childhood: a community study. J Consult Clin Psychol 2005; 73: 400-10. 